\title{
COMPARISON OF CONVENTIONAL AND ADVANCED CLASSIFICATION APPROACHES BY LANDSAT-8 IMAGERY
}

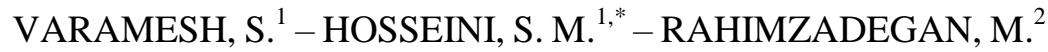 \\ ${ }^{1}$ Department of Forestry, Faculty of Natural Resources \\ Tarbiat Modares University, 64314 Noor, Mazandaran, Iran \\ ${ }^{2}$ Department of water resources \\ K. N. Toosi University of Technology, Tehran, Iran \\ *Corresponding author \\ e-mail:hosseini@modares.ac.ir \\ (Received $18^{\text {th }}$ Oct 2016; accepted $15^{\text {th }}$ Apr 2017)
}

\begin{abstract}
Over the last few years, most areas of Iran including Golestan province have posed considerable risks to human use and future development. Therefore, several reliable techniques are required to quantify, monitor and update land use maps of these areas to explore rates of environmental retreats. In this study, Landsat-8 ETM+ imageries of 2013 were consequently processed via Object Based Image Classification (OBIC) as an advanced approach and Maximum Likelihood Classification (MLC) as a conventional pixel based approaches to classify land use in Golestan province in Northeastern of Iran using an ENVI 4.8 and eCognition software packages. Overall accuracy and kappa coefficients were calculated to assess these approaches, which were respectively $94.69 \%$ and 0.93 for OBIC and $81.53 \%$ and 0.75 for MLC. In addition, accuracy rate over $85 \%$ indicates satisfactory for land use mapping and planning purposes. Our result showed that pixel-based classification approach do not lead to sufficiently accurate land use maps; and land use mapping using OBIC approach provides better classification accuracy especially when we have an extensive study area. Thus, development of this approach is appropriate for satellite images with moderate resolution.
\end{abstract}

Keywords: Object Based Image Classification, pixel based approaches, land use classification, Golestan province

\section{Introduction}

Land use landscapes, over the last five decades, have been transformed by economic and social developments (Gaughan, 2006; Wright, 2005). These alterations are important components of land use disturbance and global environmental changes (Foley et al., 2005; Moran, 2005; Cai et al., 2017).

Land use mapping is the first procedure in land use studies and thus forms principles for many earth science studies (Mohammady et al., 2014). There are essential components integrated on the requirement basis to drive several incremental indexes for land resource. Image classification is an important task for preparing land use that is useful in many aspects of global change studies and environmental applications (Pakhale and Gupta, 2010).

At present, it is clearly known that land-use classification can be accurately done by using satellite remote sensing imagery. One of the appropriate satellite sensors for such purposes is the Enhanced Thematic Mapper pluse (ETM+) on board of Landsat-8 satellite platforms (Coultera et al., 2016). Spatial and temporal resolution, availability and coverage of the Landsat data provide instrumental information for detailed land-use studies (Guo et al., 2009; Julien, 2011; Petropoulos et al., 2011; Coultera et al., 2016). 
There are several approaches for image classification, which comprises conventional techniques such as ISODATA and MLC, as well as advanced approaches such as OBIC (Lillesand et al., 2004). The conventional techniques only use gray values, but the advanced approaches classification investigates the texture, tone etc. Conventional techniques do not use of semantic information in the image, so they are not suitable for deal with the inherent heterogeneity within typical land use units (Franklin et al., 2003).

The OBIC has developed appropriate for moderate- to high-resolution satellite imagery (Baatz et al., 2004; Benz et al., 2003). Advanced approaches classification includes segmenting an image into objects. These objects have geographical features such as shape and length (Baatz et al., 2004). Many studies have revealed that an objected orient approach based on image segmentation has greater potential for land use mapping compare topixel-based approaches and can improve the accuracy of land use mapping (Oruc et al., 2004; Im et al., 2008; Zhou et al., 2008). Yu et al. (2016) claimed that OBIC method has higher accuracy and efficiency, so effectively incorporates spatial information and expert knowledge. The results of Watmough et al. (2017) revealed that OBIC consistently high accuracies for images with varying characteristics. In this method, homogeneous image objects at a chosen resolution get extracted first and then classified. In addition to spectral information in pixel- based technique, this allows a plenty of ancillary data, such as shape, context, texture, area and other object layers data to get derived from objects and get used in image classification (Shackelford and Davis, 2003; Cai et al., 2017).

Given that the Golestan province that is one of the fastest growing province of Iran in socio-economic shocks, advancement of satellite imagery in conjunction with pixelbased, as well as OBIC using ENVI 4.8 and eCognition software can be used to analyze the land use classification of this region, the main purpose of this study is therefore to investigate the performance of pixel-based and OBIC approaches for land-use mapping of this area.

\section{Material and Method}

\section{Study area}

The study area is located on northeast of Iran (Figure 1). It is located between latitudes $36^{\circ} 30^{\prime}$ to $38^{\circ} 10^{\prime} \mathrm{N}$ and the longitudes $53^{\circ} 50^{\prime}$ to $56^{\circ} 20^{\prime} \mathrm{E}$ and approximately covers $21400 \mathrm{~km}^{2}$. Altitude varies is about -40 to $3800 \mathrm{~m}$ a.s.l. The climate is temperate with mean annual temperature of $16.88^{\circ} \mathrm{C}$ and mean annual precipitation of $454 \mathrm{~mm}$.

The Golestan province is a major agricultural center but includes substantive forest cover, residential areas, barren lands, rangelands and aquatic ecosystems of all sizes and densities. Our study site has been strongly influenced by socioeconomic changes. These characteristics make this province a suitable study case for comparative assessment of land use changes. In addition, the reasons for choosing this province are its environmental sensitivity and increasing tourist activity. 


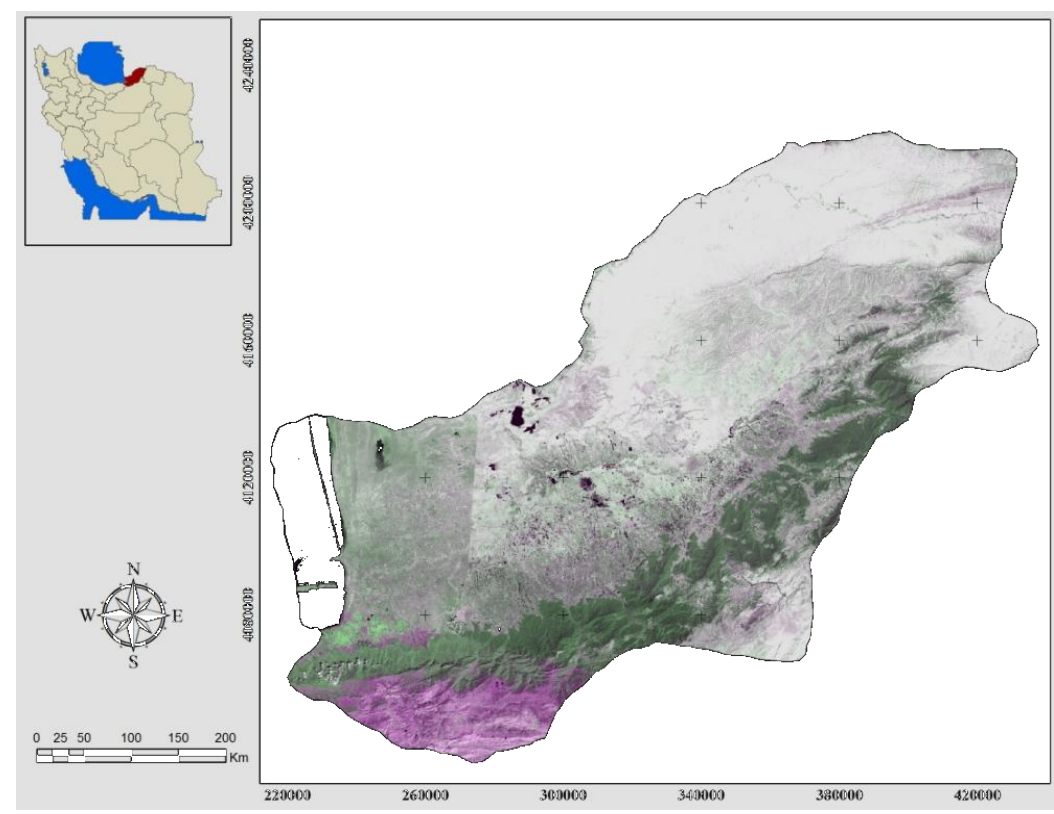

Figure 1. Location of Golestan province in northeast of Iran

\section{Data}

The available data are four image scenes coming from the Enhanced Thematic Mapper plus (ETM+) sensor on board of Landsat-8 satellite. The images were obtained in July 22, 2013 from the United States Geological Survey (USGS) Earth Resources Observation and Science Data Centre (EROS) (http://eros.usgs.gov/). However, 240 training samples were collected from study area using Land Surveying GPS and Google Earth (Chen et al., 2011; Brandt et al., 2013). Training samples were collected equally over the area with different slopes and altitudes. Approximately two-thirds of data are used for classification and the rest will be used for accuracy assessment. The number of training samples is dependent on area of each land use type and difference of spectral characteristic. Thus, if the study area is heterogeneous and have a large area, we will need many training samples.

\section{Pre-processing of satellite images}

At the first step, DNs were converted into At-Satellite Radiance using following equation (Kolios and Stylios, 2013):

$$
R=\{(R \max -R \min ) \mid(D N \max -D N \min )\} \times(\mathrm{DN}-\mathrm{DNmin})+R \min
$$

Where: $\mathrm{R}$ (units: $\mathrm{W} \mathrm{m} \_2 \mathrm{sr} \_1 \mu \mathrm{m} \_1$ ) is the radiance at the top of the atmosphere; Rmax, Rmin are band specific spectral radiances (Markham and Barker, 1987); and DNmax, DNmin are quantized calibrated digital numbers that are found in the metadata file on each of the image scene.

Then following equation was used to convert sensor radiance to surface reflectance (Song et al., 2001):

$$
\rho=\pi \times \frac{(\text { Rsat }-R p)}{T v} \times\{(\text { Eo } \times \operatorname{Cos} \theta \times T z)+\text { Edown }\}
$$


Where: $\rho$ is the surface reflectance; $\mathrm{Rp}$ is the path radiance in $\mathrm{W} \mathrm{m}_{-} 2 \mathrm{sr} 1 \mathrm{~mm} \_1$; $\mathrm{Tv}$ is the atmospheric transmittance from the land (or atmospheric) surface toward to the satellite sensor; $\mathrm{Tz}$ is the atmospheric transmittance in the illumination direction $\mathrm{W}$ $\mathrm{m} \_2 \mathrm{sr} \_1 \mathrm{~mm} \_1$; Edown is the down-welling diffuse irradiance in $\mathrm{Wm} \_2 \mathrm{sr} \_1 \mathrm{~mm} \_1$; Eo is the exo-atmospheric solar irradiance and $\theta$ is the solar zenith angle (Kolios and Stylios, 2013).

\section{Calculation of indices}

There are numerous indices to identify categories of vegetation and discriminate land types using satellite imagery (Payero et al., 2004; Solaimani et al., 2011).

In this study, NDVI (normalized difference vegetation index) and BI (Brightness Index) were used, which are focusing on the vegetation and soil type according to the following equations, see Figure 2:

$$
\begin{gathered}
N D V I=\frac{(\text { Pnir }- \text { P red })}{(\text { Pnir }+ \text { Pred })} \\
B I=\left\{(\text { Pred })^{2}+(\text { Prreen })^{2}+(\text { Pred })^{2}\right\}^{1 / 2} /(3)^{1 / 2}
\end{gathered}
$$
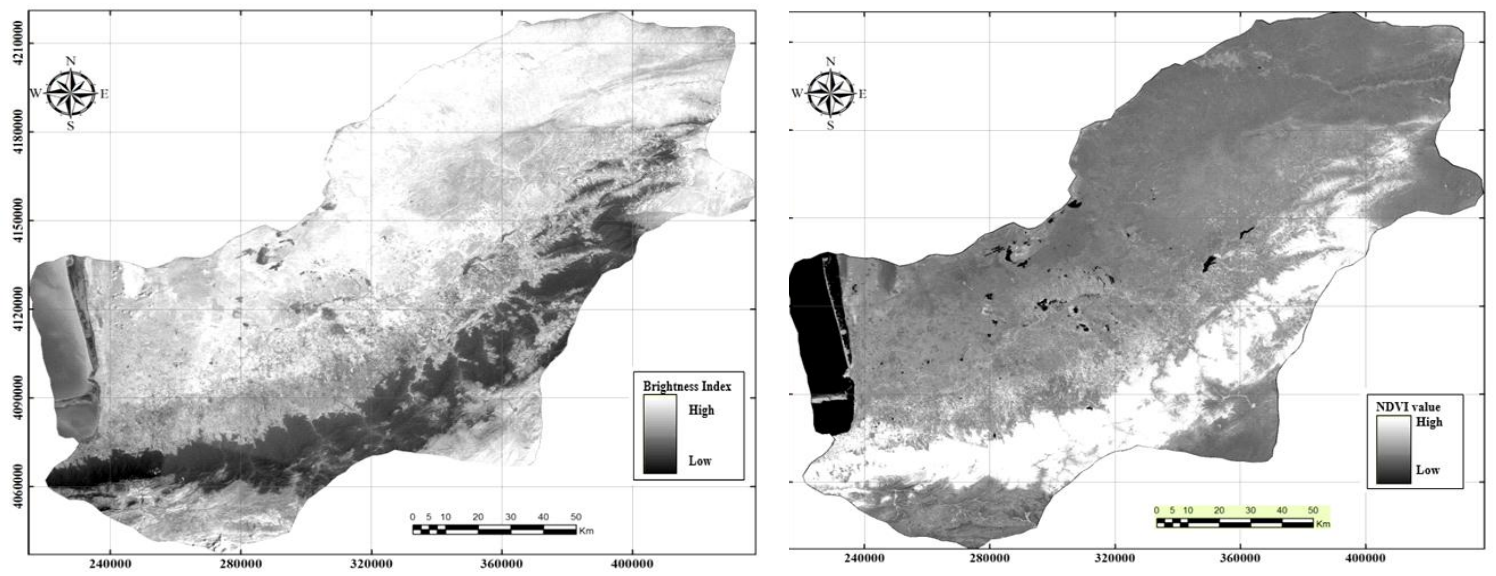

Figure 2. BI and NDVI maps of study area

\section{Image classification}

The bands of Landsat ETM+ images and indices were stacked and classification procedure was done on stacked file.

Determination of the land use classes is the first step of classification procedure that represents sufficiently every discrete land surface type of the study area. A visual examination and expert's knowledge helped us out to choose the representative classes depicted at the satellite images. Additionally, the complexity of the surface characteristics and the $30 \mathrm{~m}$ spatial resolution of Landsat images led us to select six well-discriminated land use types.

In this study, ENVI 4.8 software has been used to perform separability tests (ENVI User's Guide, 2009) on sample pixels using indices, involving NDVI and BI. 
After collecting each of class training samples, image classification was done. Then two classifiers, including MLC and OBIC, were used to prepare land use mapping.

\section{Maximum Likelihood Approach}

MLC was used for pixel-based classification (Petropoulos et al., 2012; Rojas et al., 2013). MLC presumes that the statistics for each class in each band are normally distributed and then calculates the probability that a given pixel belongs to a specific class. MLC defines the means and variances of the classes from training samples, and then, those are used to compute the probabilities of belonging to a certain class for every pixel in the satellite image (Petropoulos et al., 2012).

\section{Object-Based Image Classification}

Classification using OBIC method is the process of classifying image objects rather than individual pixels. Image objects are created through multi-resolution segmentation, which is the process of grouping adjacent pixels with similar qualities based on information from input layers.

The benefit of OBIC in comparison to pixel- based classifiers is that the image objects contain more information than spectral information provided by single pixels. Further spectral information, abbreviated of pixels collection creating the image object, each image object also contains information including texture, size, shape, and context of that image object to adjacent image objects. The spectral and spatial attributes of each image object are utilized to assign the object to a specific classification category, paralleling partly the human visual cognitive process. Preferences of this technique are more strong classifications due to the increased information and reduced units' number in the number of units to be classified. To do this study, image segmentation and objectbased classification was performed using eCognition, produced by Definiens Imaging.

Input data to the eCognition project consisted of mentioned stacked file that were used for the object-based classification. These layers were equally weighted in their contribution to the segmentation process.

Image segmentation was performed firstly to produce larger image objects, which were used in a basic binary classification to detect classes. The results of this classification were used to assist with a more detailed classification process based on smaller image objects. The eCognition allows creating objects at different sizes depending on user specified variables. These comprise scale parameters determining maximum size of the objects and composition of the homogeneity yardstick, which uses settings of compactness, shape, color, and smoothness that roughly determine the shape of the objects using spectral and shape information.

The appointment of these parameters to generate image objects is based on input data, what features are to be identified, knowledge of the software and the classification procedure to be followed. ENVI 4.8, eCognition and ArcGIS 10.1 were utilized for image analyses.

\section{Results}

\section{Conventional classification}

Conventional classification of Landsat Images was determined using MLC algorithm. The results of this approach have been given in Figure 3. 


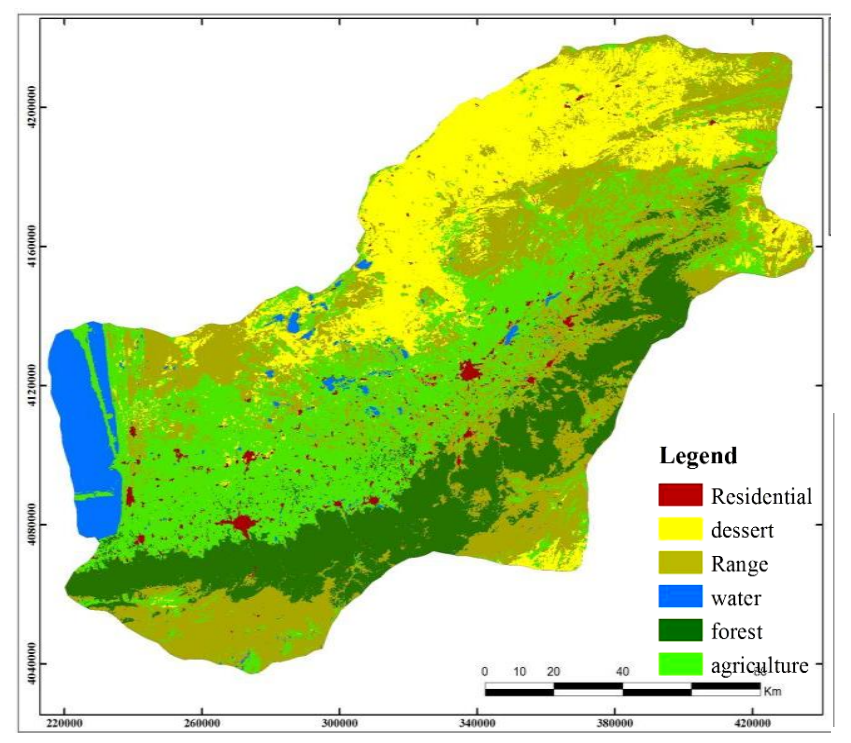

Figure 3. Main land- use classes in Golestan province of Iran extracted by ML classification

\section{Advanced classification}

OBIC segmentations were done using different scale parameters shown in Table 1.

Table 1. Segmentation Parameters applied for OBIC classification

\begin{tabular}{cccccc}
\hline Level & Scale parameter & color & Shape & smoothness & Compactness \\
& & & & & \\
\hline Level1 & 5 & 0.7 & 0.3 & 0.9 & 0.1 \\
Level2 & 10 & 0.5 & 0.5 & 0.5 & 0.5 \\
Level3 & 25 & 1.0 & 0 & 0.5 & 0.5 \\
\hline
\end{tabular}

The results of land use map of OBIC classification are shown in Figure 4. Same training samples were used to compare the two classification methods.

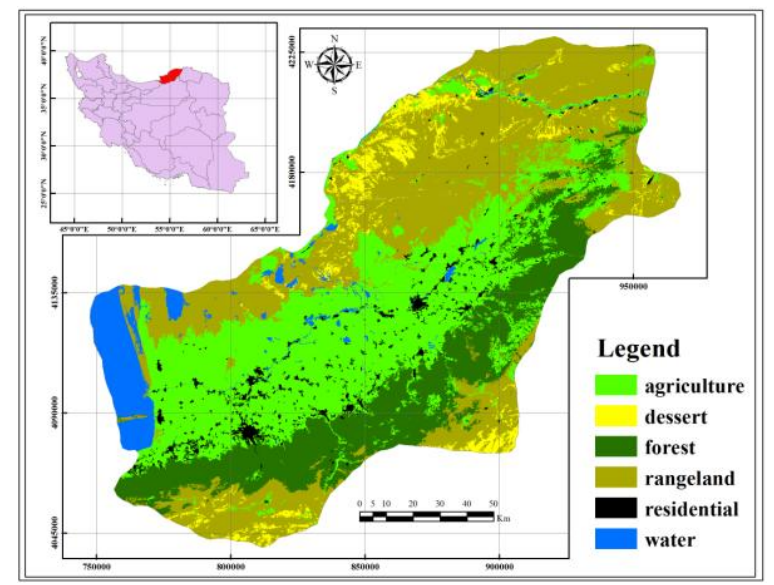

Figure 4. Main land- use classes in Golestan province of Iran extracted by OBIC classification 


\section{Accuracy assessment}

After classification step, accuracy assessment was conducted to characterize the agreement between the training samples and the classified data. For this purpose, 80 samples were selected randomly. The overall accuracy was obtained respectively $81.53 \%$ and $94.69 \%$ for land use maps prepared using ML and OBIC. In addition, kappa coefficient was 0.75 and 0.93 for land use map of ML and OBIC. These Results indicated that OBIC is more accurate than ML.

\section{Discussion}

The results of previous researches confirm accuracy of MLC and OBIC methods obtained in this study (Yu et al., 2016; Cai et al., 2017). The kappa coefficient of the land use map of OBIC was over 0.85, satisfactory for land use classification (Anderson et al., 1976). Likewise, the kappa coefficient of MLC was 0.75, closer to standard. In several reported on land use mapping, the kappa coefficient is lower than standards. For example, Cingolani et al. (2004) showed kappa for maximum likelihood 0.74. In the study of Rozenstein and Karnieli (2010), the kappa coefficient was 0.65 for ISODATA, and 0.53 for maximum likelihood, 0.68 for synthetic method. The kappa coefficient in the study of Sun et al. (2011) was 0.82 for maximum likelihood model. Huang et al. (2010) obtained 0.76 for the kappa coefficient.

This study proved that the object-oriented approach is very effective for land use mapping of Golestan province using classification of satellite imagery. When this imagery is used in heterogeneous areas, pixel-based classification methods, which only use spectral data, have very limited advantage (Zhou et al., 2008). This is because the spectral properties among different land uses could be very similar, while spectral variation within the same land use or object might be higher (Zhou and Troy, 2008). Instead, as was observed, using object-oriented approach, the grouping of pixels into objects reductions the variance of same land use, using averaging the pixels into the objects (Watmough et al., 2017). Moreover, due to using objects instead of pixels, we can use shape metrics, spatial relations and expert knowledge to contribute to classification, all of them which are essential in discriminating between various land uses with same spectral response properties (Zhou et al., 2008; Zhou and Troy, 2008).

There is a reciprocal dependency between classification and segmentation: the attributes and the quality of attributes used to estimate and classify image objects directly depend on the objects and how they were formed before (Baatz, 2008). According to the complicacy and uncertainties of image analysis problems, it is obvious further complicated models and semantics are needed in many cases (Franklin et al., 2000; Güler et al., 2007).

Despite the successful applications of this method, it should be considered that the quality of the image sources remains an important factor for land use mapping (Coultera et al., 2016). Considerable contrast that can be attained between classes and homogeneity of the classes are the factors affecting the success of different approaches.

The relative accuracy is estimated in this study based on the comparison between the processing derived classes and the classes visually interpreted from the original images. In other words, in the world applications, the perfect accuracy of the geographical position of the derived classes is essential (Hajek, 2005; Kamagata et al., 2005; Yuan, 2006). 
To the best of our knowledge, the present study is the first effort to identify land use mapping appling OBIC method and such spatial resolution, focusing exclusively on Golestan province. In addition, because high accuracy of OBIC method that obtained in classification of study are land uses, our study also prepares an example of how combining Landsat trajectory analyses and using OBIC method can help to monitor the success of land use classification.

\section{Conclusion}

Our study demonstrated image classification using object-oriented approach with an appropriate accuracy. This suggests that it has great potential for extracting land use map from satellite imagery captured over northeast Iran. Thus, it is clear that this approach can have great application particularly with the increasing usage of moderate resolution imagery and the greater data content. This study showed that because of the specific characteristics of each study area, there are no image classifiers uniformly applicable to a wide range of applications. For this reason, we tried to meet the needs of the study by taking into account the spatial-temporal accuracy of the initial use satellite imagery as well as the pre-processing steps of the image analysis. We also examined different band combinations and vegetation/soil indices to achieve a statistically accurate classification for our study area. Further works refining the process are being continued to promote the accuracies of the object-oriented classification,. Some experiences show that remote sensing technique cannot recognize the differences among different classes in the images as humans can. However, if the procedure cannot be automated, the financial benefit of the imagery would be certainly lost. In this study, Landsat images of test field have been preprocessed in ENVI 4.8 software and then segmented with eCognition packages. In the future investigations, sensitive and unsustainable regions such as Golestan province could be targeted through the processing of high-resolution images.

\section{REFERENCES}

[1] Anderson, J. R., Hardy, E. E., Roach, J., Witmer, R. E. (1976): A land use and land cover classification system for use with remote sensor data: Geological survey professional paper 964. - United States Government Printing Office, Washington D.C.

[2] Baatz, M., Benz, U., Dehghani, S., Heynen, M., Höltje, A., Hofmann, P., Lingenfelder, I., Mimler, M., Sohlbach, M., Weber, M., Willhauck, G. (2004): eCognition Professional: User guide 4. - Definiens Imaging, Germany.

[3] Baatz, M., Hoffmann, C., Willhauck, G. (2008): Progressing from object-based to objectoriented image analysis. - In: Blaschke, T., Lang, S., Hay, G. J. (Eds.) Object-Based Image Analysis. Springer, Berlin, pp. 29-42.

[4] Benz, U. C., Hofmann, P., Willhauck, G., Lingenfelder, I., Heynen, M. (2003): Multiresolution, object-oriented fuzzy analysis of remote sensing data for GIS-ready information. - ISPRS Journal of Photogrammetry \& Remote Sensing 58(3-4): 239-258.

[5] Brandt, J. S., Haynesm, M. A., Kuemmerle, T., Waller, D. M., Radeloff, V. C. (2013): Regime shift on the roof of the world: alpine meadows converting to shrublands in the southern Himalayas. - Biological Conservation 158: 116-127.

[6] Cai, F., Vliet, J. V., Verburg, P. H., Pu, L. (2017): Land use change and farmer behavior in reclaimed land in the middle Jiangsu coast, China. - Ocean \& Coastal Management 137: 107-117. 
[7] Chen, J., Zhu, X., Vogelmann, J. E., Gao, F., Jin, S. (2011): A simple and effective method for filling gaps in Landsat ETM? slc-off images. - Remote Sensing of Environment 115(4): 1053-1064.

[8] Cingolani, A. A., Renison, D., Zak, M. R., Cabido, M. R. (2004): Mapping vegetation in a heterogeneous mountain rangeland using Landsat data: an alternative method to define and classify land-cover units. - Remote Sensing of Environment 92(1): 84-97.

[9] Coultera, L. L., Stowa, D. A., Tsaia, Y., Ibaneza, N., Shiha, H. C., Kerra, A., Benzaa, M., Weeksa, J. R., Mensahb, F. (2016): Classification and assessment of land cover and land use change in southern Ghana using dense stacks of Landsat 7 ETM+ imagery. - Remote Sensing of Environment 184: 396-409.

[10] ENVI User's Guide. (2009): ENVI on-line software user's manual. - ITT Visual Information Solutions.

[11] Foley, J. A., DeFries, R., Asner, G., Barford, C., Bonan, G., Carpenter, S. R. (2005): Global consequences of land use. - Science 309(5734): 570-574.

[12] Franklin, J., Woodcock, C. E., Warbington, R. (2000): Multi-Attribute Vegetation Maps of Forest Services Lands in California Supporting Resource Management Decisions. Photogrammetric Engineering \& Remote Sensing 66(10): 1209-1217.

[13] Gaughan, A. E. (2006): Spatial and Temporal Land-Cover Transformation in the Angkor basin: A Changing Landscape in Cambodia, 1989-2005 (Thesis). - University of Florida, Gainesville.

[14] Güler, M., Yomralığlu, T., Reis, S. (2007): Using Landsat data to determine land use/land cover changes in Samsun, Turkey. - Environmental Monitoring and Assessment 127(1): 155-167.

[15] Guo, L. Y., Wang, D. L., Qiu, J. J., Wang, L. G., Liu, Y. (2009): Spatio-temporal patterns of land use change along the Bohai Rim in China during 1985-2005. - Journal of Geographical Sciences 19(5): 568-576.

[16] Hajek, F. (2005): Object-oriented classification of remote sensing data for the identification of tree species composition. - Proceedings of ForestSat 2005 conference, May 31 - June 3, 2005, Boras, Sweden.

[17] Huang, C., Goward, S. N., Masek, J. G., Thomas, N., Zhu, Z., Vogelmann, J. E. (2010): An automated approach for reconstructing recent forest disturbance history using dense Landsat time series stacks. - Remote Sensing of Environment 114(1): 183-198.

[18] Im, J., Jensen, J. R., Tullis, J. A. (2008): Object-based change detection using correlation image analysis and image segmentation. - International Journal of Remote Sensing 29(2): $399-423$.

[19] Julien, Y., Sobrino, J. A., Jiménez-Muñoz, J.-C. (2011): Land use classification from multitemporal Landsat imagery using Yearly Land Cover Dynamics (YLCD)method. International Journal of Applied Earth Observation and Geoinformation 13(5): 711-720.

[20] Kamagata, N., Akamatsu, Y., Mori, M., Qing-Li, Y., Hoshinoy, Y., Hara, K . (2005): Comparison of pixel-based and object-based classifications of high resolution satellite data in urban fringe areas. - In: Proceedings of the 26th Asian Conference on Remote Sensing. Hanoi, Vietnam. 7-11 November 2005.

[21] Kolios, S., Stylios, C. D. (2013): Identification of land cover/land use changes in the greater area of the Preveza peninsula in Greece using Landsat satellite data. - Applied Geography 40: 150-160.

[22] Lillesand, T. M., Kiefer, R. W., Chipman, J. W. (2004): Remote sensing and image interpretation, fifth ed. - John Wiley and Sons (Asia) Pte. Ltd., Singapore.210 pp.

[23] Markham, B. L., Barker, J. L. (1987): Thematic Mapper bandpass solar exoatmospheric irradiances. - International Journal of Remote Sensing 8: 517-523.

[24] Mohammady, M., Moradi, H. R., Zeinivand, H., Temme, A. J. A. M. (2014): A comparison of supervised, unsupervised and synthetic land use classification methods in 
the north of Iran. - International Journal of Environmental Science and Technology 12(5): 1515-1526.

[25] Moran, E. F. (2005): Human-environment interactions in forest ecosystems: an introduction. - In: Moran, E. F., Ostrom, E. (Eds.) Seeing the Forest and the Trees: Human-Environment Interactions in Forest Ecosystems. MIT Press, Cambridge, MA, pp. 3-21.

[26] Oruc, M., Marangoz, A. M., Buyuksalih, G. (2004): Comparison of pixel-based and object-oriented classification approaches using Landsat-7 ETM spectral bands. Proceedings of ISPRS Conference, 19-23 July, Istanbul.

[27] Pakhale, G. K., Gupta, P. K.. (2010): Comparison of Advanced Pixel Based (ANN and SVM) and Object-Oriented Classification Approaches Using Landsat-7 Etm+ Data. International Journal of Engineering and Technology 2(4): 245-251.

[28] Payero, O. J., Neale, M. U. C., Wright, L. J. (2004): Comparison of eleven vegetation indices for estimating plant height of alfalfa and grass. - Applied Engineering in Agriculture 20(3): 285-393.

[29] Petropoulos, P. G., Kontoes, C., Keramitsoglou, I. (2011): Burnt area delineation from a uni-temporal perspective based on Landsat TM imagery classification using Support Vector Machines. - International Journal of Applied Earth Observation and Geoinformation 13(1): 70-80.

[30] Rojas, C., Pino, J., Basnou, C., Vivanco, M. (2013): Assessing land-use and -cover changes in relation to geographic factors and urban planning in the metropolitan area of Concepcion (Chile). - Implications for biodiversity conservation Applied Geography 39: 93-103.

[31] Rozenstein, O., Karnieli, A. (2010): Comparison of methods for land-use classification incorporating remote sensing and GIS inputs. - Applied Geography 31(2): 533-544.

[32] Shackelford, A. K, Davis, C. H. (2003): A combined fuzzy pixel-based and object-based approach for classification of high-resolution multispectral data over urban areas. - IEEE Transactions on Geoscience and Remote Sensing 41(10): 2354-2364.

[33] Solaimani, K., Shokrian, F., Tamartash, R., Banihashemi, M. (2011): Landsat ETM based assessment of vegetation indices in highland environment. - Journal of Advances in Developmental Research 2(1): 5-13.

[34] Song, C., Woodcock, E. C., Seto, C. K., Lenney, P. M., Macomber, A. S. (2001): Classification and land change detection using Landsat TM data: when and how to correct atmospheric effects? - Remote Sensing of Environment 75: 230-244.

[35] Sun, J., Yang, J., Zhang, C., Yun, W., Qu, J. (2011): Automatic remotely sensed image classification in a grid environment based on the maximum likelihood method. Mathematical Computation Modelling 2(4): 245-251.

[36] Watmough, G. R., Palm, C. A., Sullivan, C. (2017): An operational framework for objectbased land use classification of heterogeneous rural landscapes. - International Journal of Applied Earth Observation and Geographical information 54: 134-144.

[37] Wright, S. J. (2005): Tropical forests in a changing environment. - Trends in Ecology Evolution 20(10): 553-560.

[38] Yu, W., Zhou, W., Qian, Y., Yan, J. (2016): A new approach for land cover classification and change analysis: Integrating backdating and an object-based method. - Remote Sensing of Environment 177: 37-47.

[39] Yuan, F. (2006): Mapping impervious surface area using high resolution imagery: A comparison of object-based and per pixel classification. - Proceedings of ASPRS 2006 Annual Conference, Reno, Nevada; May 1-5.

[40] Zhou, W., Troy, A. (2008): An Object-oriented Approach for Analyzing and Characterizing Urban Landscape at the Parcel Level. - International Journal of Remote Sensing 29(11): 3119-3135.

[41] Zhou, W., Troy, A., Grove, M. (2008): Object-based Land Cover Classification and Change Analysis in the Baltimore Metropolitan Area Using Multi temporal High Resolution Remote Sensing Data. - Sensors 8(3): 1613-1636. 